\title{
Isolation and Characterization of Derivative Lines of the Onion Yellows Phytoplasma that Do Not Cause Stunting or Phloem Hyperplasia
}

\author{
Kenro Oshima, Toshiki Shiomi, Tsutomu Kuboyama, Toshimi Sawayanagi, Hisashi Nishigawa, \\ Shigeyuki Kakizawa, Shin-ichi Miyata, Masashi Ugaki, and Shigetou Namba
}

First, third, fourth, fifth, sixth, seventh, eighth, and ninth authors: Graduate School of Frontier Sciences, The University of Tokyo, Bunkyoku, Tokyo; and second author: National Institute of Agro-Environmental Sciences, Tsukuba, Ibaragi, Japan.

Current address of S. Namba: Laboratory of Bioresource Technology, Graduate School of Frontier Sciences, The University of Tokyo, 1-1-1 Yayoi, Bunkyo-ku, Tokyo, 113-8657.

Accepted for publication 26 July 2001.

\begin{abstract}
Oshima, K., Shiomi, T., Kuboyama, T., Sawayanagi, T., Nishigawa, H., Kakizawa, S., Miyata, S., Ugaki, M., and Namba, S. 2001. Isolation and characterization of derivative lines of the onion yellows phytoplasma that do not cause stunting or phloem hyperplasia. Phytopathology 91:1024-1029.

Two lines of onion yellows phytoplasma producing milder symptoms were isolated from the original line (OY-W). One has an additional characteristic, non-insect-transmissibility (OY-NIM), compared with the other (OY-M). OY-M was established after maintaining OY-W for 11 years on a plant host (Chrysanthemum coronarium) with an insect vector (Macrosteles striifrons), and OY-NIM was isolated after subsequent maintenance of OY-M in plants by periodic grafting. Polymerase chain analysis suggested that OY-NIM cannot traverse the gut or survive in the
\end{abstract}

ABSTRACT

Phytoplasmas are prokaryotes lacking cell walls that are currently classified in the class Mollicutes (1). Phytoplasmas are associated with plant diseases, and are known to cause more than 600 diseases in several hundred plant species $(15,20)$. The symptoms shown by infected plants include yellowing or reddening of the leaves, shortening of the internodes with stunted growth, smalller leaves, excessive proliferation of shoots resulting in a witches'-broom, phyllody, virescence, sterile flowers, necrosis of the phloem tissues, dieback of the branches of woody plants, and the general decline and death of the plant $(1,15,20)$. Phytoplasmas are transmitted from plant to plant by insect vectors, mainly leafhoppers and psyllids (30). They traverse the wall of the intestinal tract, multiply in the hemolymph, and pass through the salivary glands, in which they multiply further. Then, the insect vectors introduce phytoplasmas along with salivary fluids into the phloem of a new host plant (1). Usually these insect vectors do not transmit phytoplasmas transovarially, although two exceptions have been reported: aster yellows and mulberry dwarf phytoplasmas $(2,14)$.

The complex phytoplasma life cycle has made studies of phytoplasma difficult. Many attempts to culture phytoplasmas on artificial nutrient media have been tried in vain $(18,20)$. Due to the inability to culture phytoplasmas in vitro, it is difficult to mutagenize phytoplasmas for subsequent analysis of mutant genes.

Corresponding author: S. Namba; E-mail address: snamba@ims.u-tokyo.ac.jp

Publication no. P-2001-0905-02R

(C) 2001 The American Phytopathological Society hemolymph of the leafhopper. OY-W results in witches'-broom formation and stunted growth in the host plant. In contrast, OY-M and OY-NIM do not cause stunting in the host plant, although they result in witches'broom. Histopathological analysis of these lines revealed that the hyperplastic phloem tissue and severe phloem necrosis seen in OY-W did not exist in OY-M and OY-NIM. This was attributed to a reduction in the population of phytoplasma in tissues in both OY-M- and OY-NIM-infected plants. The results suggest that the cause of stunting and phloem hyperplasia may be genetically different from the cause of witches'-broom. Pulsed field gel electrophoresis analysis showed that OY-M had a smaller genome size $(\approx 870 \mathrm{kbp})$ than OY-W $(\approx 1,000 \mathrm{kbp})$. Thus, some of the $\mathrm{OY}-\mathrm{W}$ genes responsible for pathogenicity may not be present in OY-M.

Additional keywords: 16S rRNA, bushy, dwarf, mollicutes, SecA.

In the case of spiroplasma, another prokaryote of the class $\mathrm{Mol}$ licutes lacking a cell wall that is culturable, symptomless mutants or non-insect-transmissible mutants have been reported $(10,44)$. Genetic analysis of these mutants has revealed some important genes and biological aspects of insect-transmissibility and multiplication of the spiroplasma $(8,43)$. A non-insect-transmissible mutant of spiroplasma was isolated by periodic grafting of the plant host in the absence of the insect vector (40), and the mutant had a large chromosomal inversion and deletions presumably created by homologous recombination (44). Similar phenomena accompanied by genetic diversity have been reported in other mollicutes $(26,45)$. This strongly suggests the possibility of isolating natural mutant phytoplasmas.

Miyahara et al. (21) found onion yellows phytoplasma (OY-W, for OY phytoplasma wild-type line) in Saga Prefecture, Japan, associated with onion yellows disease. It is transmitted by the leafhopper vector Macrosteles striifrons, and it induces a variety of symptoms on its plant hosts, including virescence, yellowing, phyllody, stunting, and proliferation. OY-W was identified as belonging to AY subgroup of group I phytoplasmas using 16S rRNA sequences (34).

In this study, we report on a line (OY-M, for OY phytoplasma mild-symptom line) derived from OY-W that produces milder symptoms, and on a non-insect-transmissible line (OY-NIM, for OY phytoplasma non-insect-transmissible and mild-symptom line) derived from OY-M. Each line was characterized and compared with the original OY-W strain with respect to symptoms, histopathological features, morphology of phytoplasma body, genome size, insect transmission, and multiplication in insects. Immunohistochemical analysis of these lines revealed that the hyperplasia 
of the phloem tissue (excessive phloem formation) observed in plants infected with OY-W was nonexistent in plant infected with either OY-M or OY-NIM.

\section{MATERIALS AND METHODS}

Phytoplasma isolates. OY-W was maintained in a greenhouse by infesting garland chrysanthemum (Chrysanthemum coronarium) three to four times a year using the leafhopper vector $M$. striifrons. During the maintenance of OY-W, several lines showing symptoms different from those produced by the original OY-W were isolated (data not shown). A line producing mild symptoms, OYM, was isolated after maintaining OY-W for 11 years. Since then, OY-M has been maintained in a similar manner. Some plants infected with OY-M were subjected to continuous graft transmission without use of the insect vector. Subsequently, a non-insect-transmissible line, OY-NIM, was identified 2 years later. Shoots exhibiting symptoms of OY-M infection were grafted to healthy garland chrysanthemums every 2 months. OY-NIM has been maintained in garland chrysanthemum and propagated by grafting. Alternatively, it has been maintained by tissue culture with surface sterilizing because maintaining by only grafting would cause the accumulation of other plant diseases. In tissue culture, surfacesterilized shoots are cultured on Murashige-Skoog (MS) medium supplemented with $2 \%$ sucrose.

Insect transmission analysis. Phytoplasma-free leafhopper vectors, $M$. striifrons, were obtained from freshly hatched eggs and maintained at $25^{\circ} \mathrm{C}$ with a photoperiod of $16 \mathrm{~h}$ light, $8 \mathrm{~h}$ dark. Second- and third-instar nymphs of the insect were reared on diseased garland chrysanthemums for 5 to 7 days to acquire the phytoplasmas (acquisition feeding). They were subsequently transferred to healthy plants for 28 days to allow the phytoplasmas to multiply and the insects to become inoculative (this is longer than the 14- to 15-day average incubation period of OY phytoplasma in insects). Ten leafhoppers were caged together on each plant with three to five leaves, and obliged to feed for 5 to 7 days to deposit the phytoplasmas (inoculation feeding). Finally, the plants were sprayed to kill the insects and transferred to a greenhouse $\left(20\right.$ to $\left.30^{\circ} \mathrm{C}\right)$ for approximately 2 months until symptoms developed.

Immunohistochemistry and fluorescence microscopy. Part of the secA gene of OY-W (GenBank Accession No. AB056578) was fused with a histidine tag and expressed in Escherichia coli. Immunoglobulin $\mathrm{G}$ ( $\mathrm{IgG}$ ) against the expressed SecA fragment (anti-SecA IgG) was prepared by methods described by Kakizawa et al. (13). Tissues were fixed in $4 \%(\mathrm{wt} / \mathrm{vol})$ paraformaldehyde and $0.25 \%$ glutaraldehyde in $0.1 \mathrm{M}$ sodium phosphate buffer $(\mathrm{pH} 7.4)$ overnight at $4^{\circ} \mathrm{C}$, dehydrated first through a graded ethanol series and then a 2-methyl-2-propanol series (33). They were finally embedded in Paraplast Plus (Sherwood Medical, St. Louis). Microtome sections (10 $\mu \mathrm{m}$ thick) were applied to charged slide glasses (Fisher Scientific, Pittsburgh, PA). The sections were deparaffinized in xylene, rehydrated through a graded ethanol series, washed twice in distilled water for $10 \mathrm{~s}$ each, and then three times in phosphate-buffered saline (PBS) buffer $(120 \mathrm{mM}$ $\mathrm{NaCl}, 7 \mathrm{mM} \mathrm{Na} 2 \mathrm{HPO}_{4}, 3 \mathrm{mM} \mathrm{NaH} \mathrm{PO}_{4}$, and $2.7 \mathrm{mM} \mathrm{KCl}$ ) for $5 \mathrm{~min}$ each. They were incubated in blocking buffer $(10 \%$ fetal calf serum and $0.02 \% \mathrm{NaN}_{3}$ in PBS buffer) for $30 \mathrm{~min}$ at room temperature, and incubated with a 1:1,000 dilution of anti-SecA $\mathrm{IgG}$ in the blocking buffer overnight at $4^{\circ} \mathrm{C}$. Each tissue section was washed four times for $10 \mathrm{~min}$ in PBS buffer containing $1.05 \%$ Tween 20 and incubated in the same buffer containing 1:1,000 alkaline phosphatase-coupled goat anti-rabbit IgG secondary antibody (Vector Laboratories Inc., Burlingame, CA) in the blocking buffer for $1 \mathrm{~h}$. Each section was washed four times for 10 min each in PBS buffer containing 1.05\% Tween 20 and then washed twice with alkaline phosphatase (AP) buffer $(100 \mathrm{mM}$ $\mathrm{NaCl}, 50 \mathrm{mM} \mathrm{MgCl}$, and $100 \mathrm{mM}$ Tris- $\mathrm{HCl}, \mathrm{pH}$ 9.5). For color development, sections were incubated in AP buffer containing nitroblue tetrazolium salt at $0.34 \mathrm{mg} / \mathrm{ml}$ and 5-bromo-4-chloro-3indolyl phosphate toluidinium salt at $0.175 \mathrm{mg} / \mathrm{ml}$ at room temperature in the dark. After color development, the reaction was stopped by immersing the slides in Tris-EDTA (TE), pH 7.5. The sections were dehydrated through a graded ethanol series and then mounted in Eukitt (O Kindler $\mathrm{GmbH} \& \mathrm{Co}$., Freiburg, Germany).

The deparaffinized and rehydrated sections were stained with a $0.1 \%$ solution of water-soluble aniline blue dye (Wako Pure Chemical Industries Ltd., Osaka, Japan) in $0.1 \mathrm{M} \mathrm{K}_{3} \mathrm{PO}_{4}$ (pH 11.6) (19). Twenty percent glycerin was added to facilitate storage of slides without desiccation. Callose deposition was observed by epifluorescence microscopy (BX60 Olympus Optical Co. Ltd., Tokyo) after 20 min of staining.

Isolation of DNA from phytoplasma. The procedure described by Kirkpatrick et al. (16) was modified to isolate phytoplasma DNA from diseased plant tissues. Fresh leaf tissue from a symptomatic garland chrysanthemum was frozen in liquid nitrogen and ground with a mortar and pestle. Then, extraction buffer $(0.1 \mathrm{M}$ sodium phosphate buffer, $\mathrm{pH} 7.6$, containing $10 \%$ sucrose, $50 \mathrm{mM}$ L (+)-ascorbic acid, $2 \%$ polyvinylpyrrolidone, and $0.15 \%$ bovine serum albumin) was added. After low-speed centrifugation $(1,500 \times g, 4 \mathrm{~min})$, the supernatant was filtered and high-speed centrifugation $(18,000 \times g, 25 \mathrm{~min})$ was performed. The resultant pellet was resuspended in buffer $(15 \mathrm{mM}$ Tris- $\mathrm{HCl} \mathrm{pH} 8.0,3 \mathrm{mM}$ EDTA, and $1 \%$ sodium dodecyl sulfate) and incubated on ice for at least $10 \mathrm{~min}$. Phenol/chloroform/isoamyl alcohol (25:24:1, $\mathrm{vol} / \mathrm{vol} / \mathrm{vol}$ ), chloroform/isoamyl alcohol (24:1, vol/vol), chloroform, and ethyl ether were used to extract and purify the DNA. DNA was precipitated from the aqueous phase with 2-propanol and used for the polymerase chain reaction (PCR) assay of the 16S rRNA gene.

PCR assay of the 16S rRNA gene. A region of the $16 \mathrm{~S}$ rRNA genes of phytoplasmas was amplified using a universal primer set (SN910601: 5'-GTTTGATCCTGGCTCAGGATT-3' and SN910502: 5'-AACCCCGAGAACGTATTCACC-3') (23,24). The PCR reaction was performed in a thermal cycler (GeneAmp PCR SYSTEM 9600; Applied Biosystems, CA). The reaction mixtures were initially denatured at $94^{\circ} \mathrm{C}$ for $90 \mathrm{~s}$, followed by 30 cycles consisting of denaturation at $94^{\circ} \mathrm{C}$ for $30 \mathrm{~s}$, annealing at $65^{\circ} \mathrm{C}$ for $30 \mathrm{~s}$, and extension at $72^{\circ} \mathrm{C}$ for $1 \mathrm{~min}$, and an additional extension step at $72^{\circ} \mathrm{C}$ for $7 \mathrm{~min}$.

Pulsed field gel electrophoresis. Pulsed field gel electrophoresis (PFGE) was performed to isolate the chromosomal DNA of the phytoplasmas using the modified method of Neimark and Kirkpatrick (25). A phytoplasma-enriched fraction was prepared by differential centrifugation as described in the previous section on isolating DNA. The fraction was mixed with an equal volume of melted agarose to form gel blocks and embedded in $1 \%$ (wt/vol) SeaPlaque GTG agarose (FMC, Rockland, ME). The chromosome became linear in this isolation process, so linearization was not necessary (29). The gel was electrophoresed in $0.5 \times$ Tris-borate EDTA (TBE) buffer for $22 \mathrm{~h}$ at 6 volts/cm in a CHEF DRIII PFGE system (Bio-Rad Laboratories, Hercules, CA) with a switch time of 50 to $90 \mathrm{~s}$. The gel was stained with SYBR Green I Nucleic Acid Gel Stain (FMC) for at least $1 \mathrm{~h}$ to visualize the fulllength phytoplasma chromosomal DNA. The position of the fulllength chromosome was confirmed by PCR assay of the $16 \mathrm{~S}$ rRNA gene as follows. After electrophoresis, the gel blocks containing the phytoplasma genome were cut from the gel and incubated in $\beta$-agarase buffer (Nippon Gene, Toyama, Japan) for $1 \mathrm{~h}$. The blocks were then incubated at $70^{\circ} \mathrm{C}$ for $15 \mathrm{~min}$ to melt them. One unit of $\beta$-agarase (Nippon Gene) was added for each $200 \mathrm{mg}$ of gel, and incubated at $45^{\circ} \mathrm{C}$ for $1 \mathrm{~h}$. The samples were cooled on ice for 5 to $10 \mathrm{~min}$ and centrifuged to eliminate the gel debris. Finally, the DNA was precipitated from the supernatant and used as the PCR template. 


\section{RESULTS}

Symptoms and stability of OY-M. After maintaining the original strain, OY-W, for 11 years, a line producing milder symptoms, OY-M, was isolated. Plants infected with OY-W showed typical symptoms of leaf yellowing, witches'-broom, and stunted growth (Fig. 1B). On the other hand, plants infected with OY-M still produced many lateral shoots, but showed mild leaf yellowing and almost no stunting (Fig. 1C). The host range and incubation period of OY-M were not significantly different from those of OY-W (37). OY-M has been maintained on garland chrysanthemums with periodic transmission using the leafhopper vector for more than 4 years, and the symptoms are reproducible.

Isolation of OY-NIM and evidence of its non-leafhopper transmissibility. Another line of phytoplasma, OY-NIM, was isolated from OY-M after successively grafting OY-M-infected plants for 2 years in the absence of insects. The symptoms of plants infected with OY-NIM (Fig. 1D) were quite similar to those of plants infected with OY-M. However, healthy plants exposed to leafhoppers that fed on a plant infected with OY-NIM were symptomless, even 3 weeks post inoculation feeding (PIF). This strongly suggests that OY-NIM is not transmitted by the insect vector.

To examine the insect transmissibility of OY lines in detail, garland chrysanthemum plants were exposed to 60 leafhoppers that had been obliged to feed for 10 days on plants infected with OY-W, OY-M, or OY-NIM. Subsequently, each plant was observed for symptom development (Table 1) and this experiment was repeated four times. In plants inoculated with OY-W or OY$\mathrm{M}$, symptoms appeared 2 weeks PIF and typical symptoms developed 3 weeks PIF. In the OY-NIM inoculated plants, however, no symptoms developed 3 weeks PIF (Table 1). PCR was also used to examine plants for phytoplasma infection with primers specific to the phytoplasmal 16S rRNA gene at 2 weeks PIF (Table 1 and Fig. 2, lanes 7 to 10). A specific band of the 16S rRNA gene was amplified from the DNA of plants inoculated with OY-W or OY-M (Fig. 2, lanes 8 and 9), but no band was amplified from plants exposed to insects that fed on OY-NIM-infected plants (Fig. 2, lane 10). These results show that the plants inoculated with leafhoppers that previously fed on an OY-NIM-infected plant were free from OY-NIM and that OY-NIM is not transmissible by the leafhopper vector.

To investigate the existence of phytoplasma lines in the insect vector after acquisition feeding, DNA extracted from leafhopper hosts was analyzed by PCR with primers specific to the phytoplasmal 16S rRNA gene (Fig. 2, lanes 1 to 6). Although leafhop-

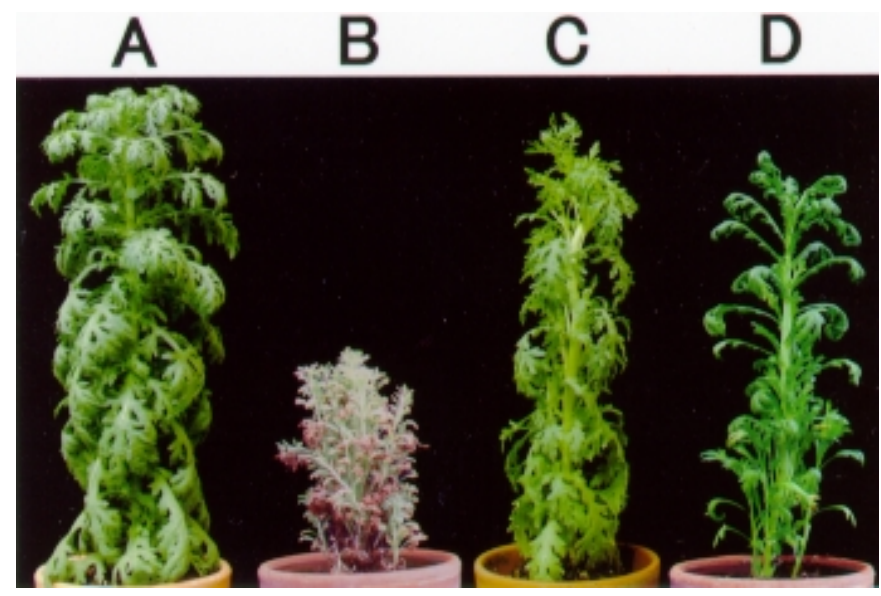

Fig. 1. Typical symptoms of onion yellows (OY)-W-, OY-M-, and OY-NIMinfected garland chrysanthemums. The photograph shows $\mathbf{A}$, a healthy plant, B, OY-W-infected, C, OY-M-infected, and D, OY-NIM-infected plants. Compared with the symptoms of OY-W infection, the plant infected with OY-M shows almost no stunting and milder symptoms. pers that fed on plants infected with OY-NIM were sampled 1 day, 2 weeks, and 3 weeks post acquisition feeding (PAF), no DNA fragment was amplified from leafhoppers that fed on OY-NIMinfected plants (Fig. 2, lanes 4 to 6). On the other hand, a $16 \mathrm{~S}$ rRNA gene fragment was amplified in control lanes (Fig. 2, lanes 2 and 3 ).

OY-W caused excessive phloem formation, but OY-M and OY-NIM did not. An antibody raised against SecA, an essential protein of the protein export pathway, from OY-W was reacted with cross sections of the stem of OY-W-infected garland chrysanthemum, and antigen was detected with an alkaline phosphatasemediated reporter system. This analysis showed that OY-W localized specifically in phloem cells, as reported previously (Fig. 3C) (20). Anti-SecA antibody is thought to be effective for studying the relationship between symptoms and the spatial distribution of phytoplasma. Thus, symptoms observed in the phloem tissue and the localization of phytoplasma were studied in plants infected with OY-W, OY-M, or OY-NIM using the anti-SecA antibody and aniline blue, which stains callose specifically (19). In OY-Winfected plants, the phloem of each vascular bundle was connected to that of other vascular bundles by excessive phloem formation and the phloem formed a meandering band (Fig. 3A and C). The number of cells infected with phytoplasma was increased in proportion to the hyperplasia of phloem cells. Necrosis was observed in the abaxial part of the phloem and callose accumulated on the cell wall or in the intercellular space of necrotic cells (Fig. 3A). The vascular bundles of lateral shoots were often observed abaxially adjacent to the necrotic phloem region (Fig. 3A and C). On the other hand, phloem hyperplasia was not observed in OY-M- or OY-NIM-infected plants (Fig. 3G and $\mathrm{H}$ ), and necrosis was not prominent in plants infected with these two lines (Fig. 3E and F). Although necrosis was not severe, callose accumulation was observed in the cells abaxially adjacent to OY-M- or OY-NIMinfected cells, and phytoplasmas were not detected in cells containing callose accumulations (Fig. 3E and F). The intensity of immunohistochemical signals showed that the phytoplasma population in a cell varied among phloem cells, even in the same tissue. In contrast, the density of phytoplasmas per cell was not significantly different among the three lines (Fig. 3), and this was consistent with electron microscopy observations (data not shown). These results indicate that the phytoplasma population per tissue was lower in OY-M- and OY-NIM-infected plants than in OY-Winfected ones, because OY-M and OY-NIM did not induce hyperplasia of phloem cells, where phytoplasmas live.

PFGE of full-length chromosomes. The deletion of a signifycant region in the chromosome has been reported in mutants of Spiroplasma citri (44). This prompted us to check the electrophoretic mobility of the full-length chromosomal DNA of OY lines. After PFGE, the position of the full-length chromosomes was confirmed using the PCR product of the 16S rRNA gene. Using $S$. cerevisiae size markers for comparison, the full-length genomes of OY-W and OY-M were positioned at 1,000 and $870 \mathrm{~kb}$, respectively (Fig. 4), and this result clearly shows that OY-M has a smaller genome than OY-W. This suggests that the periodical maintenance of OY-W introduced a mutation or re-

TABLE 1. Symptom development on garland chrysanthemum plants inoculated with various lines of onion yellows (OY) phytoplasma ${ }^{\mathrm{a}}$

\begin{tabular}{lccc}
\hline & \multicolumn{3}{c}{ Symptoms at days after transmission $^{\mathrm{b}}$} \\
\cline { 2 - 4 } Inoculum & 7 & 14 & 21 \\
\hline OY-W & $-(0)$ & $+(4)$ & $++(4)$ \\
OY-M & $-(0)$ & $+(4)$ & $+(4)$ \\
OY- NIM & $-(0)$ & $-(0)$ & $-(0)$ \\
\hline
\end{tabular}

Four garland chrysanthemum plants were used in each test.

b Symptoms of plants inoculated with phytoplasma; $-=$ no symptoms, $+=$ mild symptoms, and $++=$ stunting and systemic leaf yellows. Number of plants showing symptoms is shown in parenthesis. 
arrangement and reduced the size of the chromosome. Alternatively, the field OY phytoplasma population can be a mixture of many variants and OY-M, already having existed in the population, was selected by random genetic drift associated with laboratory-scale maintenance. Judging from the PFGE profiles of genomic DNA, however, OY-W and OY-M populations appear homogeneous.

\section{DISCUSSION}

Since the discovery of phytoplasmas, phenotypic mutants of these bacteria have long been sought. We found a line from OY-W producing weak symptoms after long-term maintenance by periodical leafhopper transmission, and named the line OY-M $(17,37)$. OY-M-infected plants showed weak symptoms, although there were no differences between OY-W and OY-M in the phytoplasma's morphology by electron microscopy (data not shown), in range of hosts (37), and in incubation period (37). In this article, we showed that the differences in host symptoms between OY-W and OY-M are manifest not only in the external symptoms (yellowing of the leaves and stunted growth), but also in internal symptoms (hyperplasia of phloem cells). This characteristic of OY-M-infected plants was also observed in a plant infected with the LY2 line of lettuce yellows phytoplasma, which we reported previously, and the symptoms of LY2 were quite similar to those of OY-M (39). Excessive phloem formation accompanied by sieve-cell necrosis has been described in several phytoplasmainfected plants $(4,5,31,36,39)$, but variants that cannot induce phloem cell proliferation had not been reported before our report for the LY2 line of lettuce yellows phytoplasma (39) and this report for the OY-M line of onion yellows phytoplasma. Lack of hyperplasia in the phloem was also observed in OY-NIM, a noninsect-transmissible line originated from OY-M.

We observed the existence of phytoplasma bodies in phloem tissues with and without hyperplasia by immunohistochemically detecting the expression of $\sec A$, a phytoplasma gene indispensable for bacterial protein export (13). In addition, necrosis was not prominent in both OY-M infected and OY-NIM infected phloem (Fig. 3). The apparent correlation between phloem necrosis and hyperplasia suggested that the necrotic phloem damaged by OY-W triggered formation of replacement phloem to compensate for the lost phloem function $(3,35)$. In the OY-W-infected plants, however, the phloem increased to a quantity far larger than that in healthy plants (Fig. 3), a phenomenon which cannot be explained by the simple replacement hypothesis. Alternatively, OY-W, but not OY$\mathrm{M}$ or OY-NIM, may encode a function to stimulate growth of phloem tissues. Unusual cell proliferation is sometimes induced by infection with the bacteria Agrobacterium, Pseudomonas, Rhizobium, and Rhodococcus $(6,22,38)$. Usually, these gall-inducing bacteria have genes for phytohormone synthesis or genes related to phytohormone sensitivity. Such genes are often located on large plasmids $(>100 \mathrm{kbp})(7,11,12,46)$. Although putative megaplas-

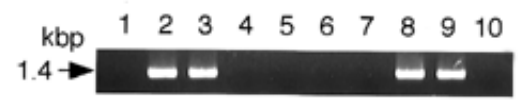

Fig. 2. Polymerase chain reaction detection of the phytoplasma $16 \mathrm{~S}$ rRNA gene in total DNA extracted from leafhoppers (lanes 1 to 6) or plants (lanes 7 to 10) with primers specific for the phytoplasma 16S rRNA gene (SN910601 and SN910502). DNA was extracted from leafhoppers 2 weeks post acquisition feeding (PAF) on a healthy plant (lane 1) or on plants infected with onion yellows (OY)-W (lane 2) or OY-M (lane 3). Leafhoppers were obliged to feed on an non-insect-transmissible (NIM)-infected plant, and total DNA was extracted 1 day (lane 4), 2 weeks (lane 5), or 3 weeks (lane 6) PAF. Leafhoppers were obliged to feed for 10 days on a healthy plant (lane 7) or a plant infected with OY-W (lane 8), OY-M (lane 9), or NIM (lane 10) and then transferred to a healthy plant and maintained for 2 weeks. Then, DNA was extracted from each plant exposed to insect feeding and subjected to $16 \mathrm{~S}$ rRNA gene analysis. mids have been identified in several other phytoplasmas (26), they have not been found in OY phytoplasma. OY-W and OY-M both have extrachromosomal DNA but the composition is not the same $(17,27,28)$. The open reading frames on the extrachromosomal DNA do not have significant homology with known genes en-
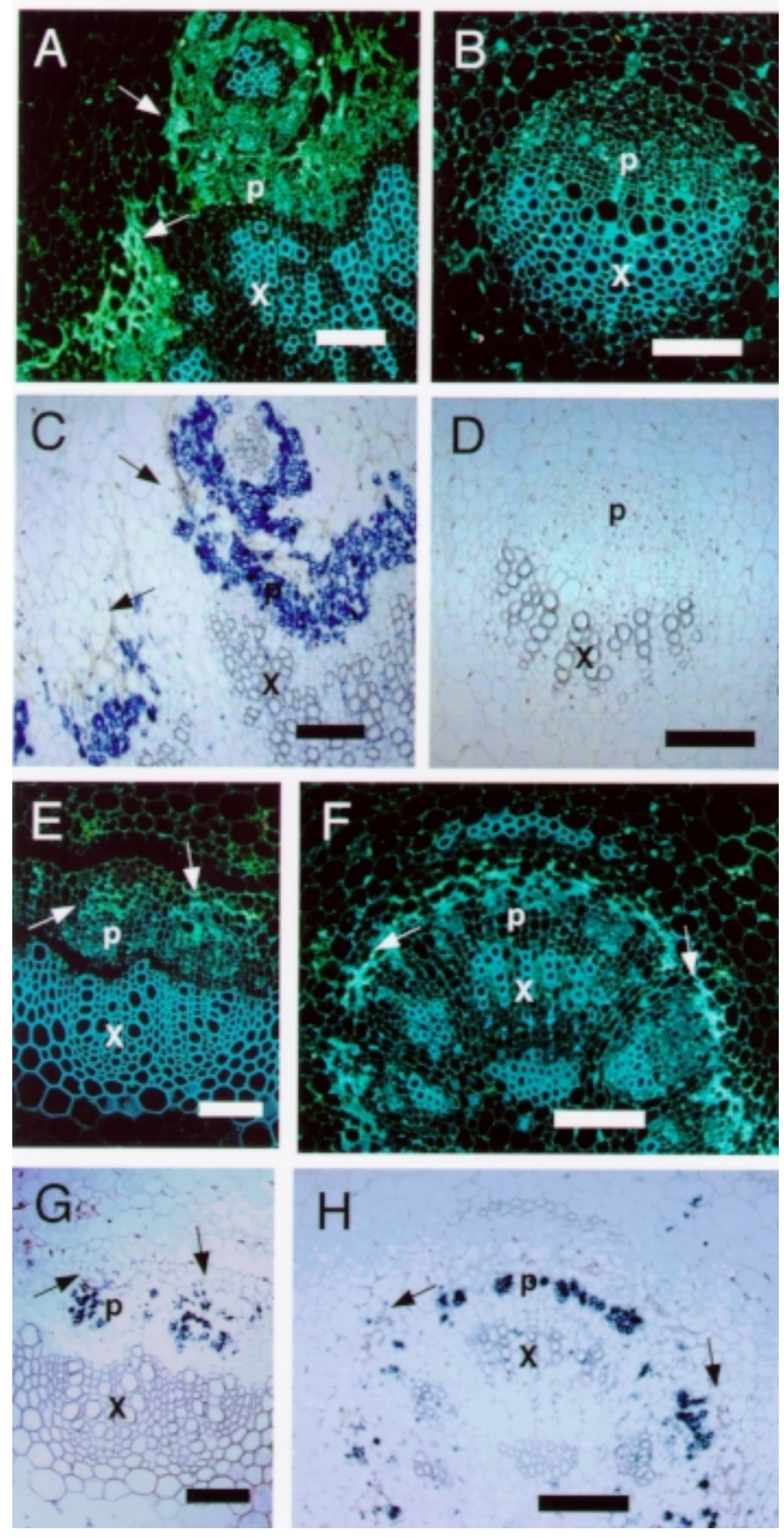

Fig. 3. Histochemical comparison of vascular bundles infected with three lines of onion yellow (OY) phytoplasma. A, B, E, and F, Callose deposition was visualized with aniline blue staining and observed by epifluorescence microscopy. Callose was observed as yellowish green fluorescence. Blue auto-fluorescence was observed in the cell wall of xylem cells. C, D, G, and H, Phytoplasma localization was investigated with anti-OY-W-SecA antibodies. A cross section of a vascular bundle was reacted with antibodies raised against SecA protein and goat anti-rabbit secondary antibody conjugated to alkali phosphatase (AP). SecA protein of OY phytoplasma was detected as blue pigmentation. A and $\mathbf{C}$ show an OY-W-infected plant; $\mathbf{B}$ and $\mathbf{D}$ show a healthy plant; $\mathbf{E}$ and $\mathbf{G}$ show an OY-M-infected plant; and $\mathbf{F}$ and $\mathbf{H}$ show an OY-NIM-infected plant. Each pair of specimens was derived from serial sections. $\mathrm{P}=$ phloem, $\mathrm{X}=$ xylem, and arrows = places where callose accumulated densely with phytoplasma infection. Phytoplasmas were not detected in cells with dense callose accumulations. Bars $=100 \mu \mathrm{m}$. 
coding phytohormones. However, the current data are insufficient to determine whether the genes related to phloem-specific cell proliferation are possessed by OY-W or not, and, in case they are, whether they are located on chromosomal or extrachromosomal DNA.

OY-M produces as many lateral shoots in infected plants as OY$\mathrm{W}$ but it does not induce stunting. One explanation for this difference could be that a decreased or a phenotypically distinct population of OY-M influences the host plant's phytohormone or nutrient concentration (or composition) in such a way that leads to different symptom expression. Alternatively, OY-W genetically encodes factors responsible for its symptoms (i.e., proliferation of lateral shoots and the arrest of internode growth) and OY-M lacks this genetic information. Studying the genetic differences between OY-M and OY-W may help us understand the mechanism of phytoplasma symptom expression.

Maintenance of OY-M by continuous grafting on host plants enabled us to isolate the non-insect-transmissible line OY-NIM. Similar non-insect-transmissible lines and a nonsymptomatic mutant have been isolated in spiroplasmas $(40,41)$. Spiroplasma citri BR3-G lost the ability to infect plants via leafhopper transmission after being maintained by periodic graft transmission for 8 years. In BR3-G, a significant portion of the chromosome of the original strain was deleted. This deletion was created by homologous recombination between two sequences that are similar to spiroplasma virus $\mathrm{SpV1}$. SpV1-like sequences have been found at multiple sites in the genomes of most $S$. citri strains $(32,42)$. These repeated sequences might play a role in the dynamic rearrangement of the genome that includes inversions, transpositions, and deletions of large DNA segments (42). The chromosomal size of OY-M was also reduced in comparison with that of OY-W. Although the existence of a phytoplasma virus has not been reported yet, natural variants of phytoplasmas are isolated during long-term maintenance, as in the case of spiroplasma. Thus, the existence of a molecular mechanism producing chromosomal aberrations in phytoplasma is likely.

OY-NIM was not detected by PCR in leafhoppers 1 day, 2 weeks, or 3 weeks PAF. The data suggest that OY-NIM cannot be acquired by the leafhopper and cannot multiply in the leafhoppers. In insect transmission, phytoplasmas must (i) survive the inges-

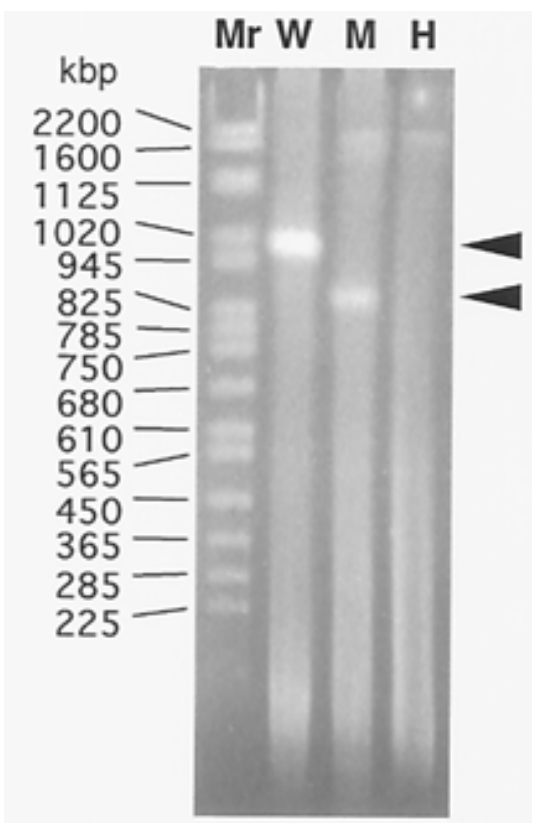

Fig. 4. Mobility analysis of full-length chromosomes by pulsed field gel electrophoresis. $\mathrm{Mr}=$ Spiroplasma cerevisiae size marker, $\mathrm{W}=$ onion yellows (OY)-W-infected plant, $\mathrm{M}=\mathrm{OY}-\mathrm{M}$-infected plant, $\mathrm{H}=$ healthy plant. Arrowheads show bands produced by the phytoplasma chromosome. tion process, (ii) be able to traverse the wall of the intestinal tract, and (iii) multiply in the hemolymph. Subsequently, they must also (iv) traverse and multiply in the salivary gland (9). The data in this paper suggest that OY-NIM must be deficient in one or some of the above steps ( $\mathrm{i}$ to iv) in the transmission process. 16S rRNA gene analysis showed that OY-NIM cannot multiply in the leafhopper at levels detectable by PCR, and this indicated that OYNIM cannot traverse the gut or survive in the hemolymph of leafhoppers. A non-insect-transmissible line of S. citri, BR3-G, could not be recovered from the hemolymph or salivary glands and is similar to OY-NIM in this regard. The lack of insect transmission of BR3-G is thought to be the result of its inability to traverse the gut and salivary gland barriers (40). On the other hand, a transposon mutant of $S$. citri, GMT 470, can maintain titers for 15 days PAF, but it is not transmissible because of its inability to be injected into the plant (10). Thus, the barriers that GMT 470 cannot overcome might not be the same as those for OY-NIM.

In conclusion, a line producing milder symptoms, OY-M, and a leafhopper-non-transmissible line producing milder symptoms, OY-NIM, were isolated from OY-W. A histopathological and immunological comparison of these lines provided us with information on phytoplasma pathogenicity. We are now able to use genetic approaches to study the pathogenicity of phytoplasmas and insect transmissibility. Furthermore, differences in the chromosomal and extrachromosomal DNA of these lines provide an opportunity to study the molecular basis of these phenomena.

\section{ACKNOWLEDGMENTS}

This work was supported by the program for the Promotion of Basic Research Activities for Innovative Biosciences (PROBRAIN) of Japan, and by grants-in-aid from the Ministry of Education, Science and Culture of Japan (09460155). We thank S. Hatano for his excellent technical assistance.

\section{LITERATURE CITED}

1. Agrios, G. N. 1997. Plant diseases caused by Mollicutes: Phytoplasmas and spiroplasmas. Pages 457-470 in: Plant Pathology. 4th ed. G. N. Agrios, ed. Academic Press, New York.

2. Alma, A., Bosco, D., Danielli, A., Bertaccini, A., Vibrio, M., and Arzone, A. 1997. Identification of phytoplasmas in eggs, nymphs, and adults of Scaphoideus titanus Ball reared on healthy plants. Insect Mol. Biol. 6:115-121.

3. Batjer, L. P., and Schneider, H. 1960. Relation of pear decline to rootstocks and sieve-tube necrosis. Proc. Am. Soc. Hortic. Sci. 76:85-97.

4. Braun, E. J., and Sinclair, W. A. 1976. Histopathology of phloem necrosis in Ulmus americana. Phytopathology 66:598-607.

5. Braun, E. J., and Sinclair, W. A. 1979. Phloem necrosis of elms: Symptoms and histopathological observations in tolerant hosts. Phytopathology 66:598-607.

6. Brown, N. A. 1927. Sweet pea fasciation, a form of crowngall. Phytopathology 17:29-30.

7. Crespi, M., Messens, E., Caplan, A. B., van Montagu, M., and Desomer, J. 1992. Fasciation induction by the phytopathogen Rhodococcus fascians depends upon a linear plasmid encoding a cytokinin synthase gene. EMBO J. 11:795-804.

8. Fletcher, J., Shaw, M. E., Baker, G. R., Dugan, K. J., Ye, F., Sha, Y., Zuck, P. D., and Myers, G. D. 1996. Molecular characterization of Spiroplasma citri BR3 lines that differ in transmissibility by the leafhopper Circulifer tenellus. Can. J. Microbiol. 42:124-131.

9. Fletcher, J., Wayadande, A., Melcher, U., and Ye, F. 1998. The phytopathogenic mollicute-insect vector interface: A close look. Phytopathology 88:1351-1358.

10. Foissac, X., Danet, L., Saillard, C., Gaurivaud, P., Laigret, F., Pare, C., and Bové, J. M. 1997. Mutagenesis by insertion of Tn4001 into the genome of Spiroplasma citri: Characterization of mutants affected in plant pathogenicity and transmission to the plant by the leafhopper vector Circulifer haematoceps. Mol. Plant-Microbe Interact. 10:454-461.

11. Gelvin, S. B. 1990. Crown gall disease and hairy root disease: A sledgehammer and a tackhammer. Plant Physiol. 92:281-285.

12. Glass, N. L., and Kosuge, T. Cloning of the gene for indoleacetic acidlysine synthetase from Pseudomonas syringae subsp. savastanoi. J. Bacteriol. 166:598-603. 
13. Kakizawa, S., Oshima, K., Kuboyama, T., Nishigawa, H., Jung, H.-Y., Sawayanagi, T., Tsuchizaki, T., Miyata, S., Ugaki, M., and Namba, S. 2001. Cloning and expression analysis of phytoplasma protein translocation genes. Mol. Plant-Microbe Interact. 14:1043-1050.

14. Kawakita, H., Saiki, T., Wei, W., Mitsuhashi, W., Watanabe, K., and Sato, M. 2000. Identification of mulberry phytoplasmas in the general organs and eggs of leafhopper Hishimonoides sellatiformis. Phytopathology 90:909-914.

15. Kirkpatrick, B. C. 1992. Mycoplasma-like organisms: Plant and invertebrate pathogens. Pages 4050-4067 in: The Prokaryotes. 2nd ed. A. Balows, H. G. Truper, M. Dworkin, W. Harder, and K. H. Schleifer, eds. Springer-Verlag, New York.

16. Kirkpatrick, B. C., Stenger, D. C., Morris, T. J., and Purcell, A. H. 1987. Cloning and detection of DNA from a nonculturable plant pathogenic mycoplasma-like. Science 238:197-200.

17. Kuboyama, T., Huang, C.-C., Lu, X., Sawayanagi, T., Kanazawa, T., Kagami, T., Matsuda, I., Tsuchizzaki, T., and Namba, S. 1998. A plasmid isolated from phytopathogenic onion yellows phytoplasma and its heterogeneity in the pathogenic phytoplasma mutant. Mol. PlantMicrobe Interact. 11:1031-1037.

18. Lee, I.-M., and Davis, R. E. 1986. Prospects for in vitro culture of plant pathogentic mycoplasmalike organisms. Annu. Rev. Phytopathol. 24: 339-354.

19. Martin, F. W. 1959. Staining and observing pollen tubes in the style by means of fluorescence. Stain Technol. 48:23-27.

20. McCoy, R. E., Caudwell, A., Chang, C. J., Chen, T. A., Chiykowski, L. N., Cousin, M. T., Dale, J. C., de Leeuw, G. T. N., Golino, D. A., Hackett, K. J., Kirkpatrick, B. C., Marwitz, R., Petzold, H., Sinha, R. H., Sugiura, M., Whitcomb, R. F., Yang, I. L., Zhu, B. M., and Seemüller, E. 1989. Plant diseases associated with mycoplasma like organisms. Pages 546-640 in: The Mycoplasmas. Vol. 5. R. F. Whitcomb and J. G. Tully, eds. Academic Press, New York.

21. Miyahara, K., Matsuzaki, M., Tanaka, K., and Sako, N. 1982. A new disease of onion caused by mycoplasma-like organism in Japan. Ann. Phytopathol. Soc. Jpn. 48:551-554.

22. Morris, R. O. 1986. Genes specifying auxin and cytokinin biosynthesis in phytopathogens. Annu. Rev. Plant Physiol. 37:509-538.

23. Namba, S., Kato, S., Iwanami, S., Oyaizy, H., Shiozawa, H., and Tsuchizaki, T. 1993. Detection and differentiation of plant-pathogenic mycoplasma-like organisms using polymerase chain reaction. Phytopathology 83:786-791.

24. Namba, S., Oyaizu, H., Kato, S., Iwanami, S., and Tsuchizaki, T. 1993. Phylogenetic diversity of phytopathogenic mycoplasmalike organisms. Int. J. Syst. Bacteriol. 43:461-467.

25. Neimark, H. C., and Lange, C. S. 1990. Pulse-field eletrophoresis indicates full-length mycoplasma chromosomes range widely in size. Nucleic Acids Res. 18:5443-5448.

26. Neimark, K., and Kirkpatrick, B. C. 1993. Isolation and characterization of full-length chromosomes from non-culturable plant-pathogenic mycoplasma-like organism. Mol. Microbiol. 7:21-28.

27. Nishigawa, H., Miyata, S., Oshima, K., Sawayanagi, T., Komoto, A., Kuboyama, T., Matsuda, I., Tsuchizaki, T., and Namba, S. 2001. In planta expression of a protein encoded by the extrachromosomal DNA of phytoplasma and related to geminivirus replication proteins. Microbiology 147:507-513.

28. Oshima, K., Kakizawa, S., Nishigawa, H., Kuboyama, T., Miyata, S., Ugaki, M., and Namba, S. 2001. A plasmid of phytoplasma encodes a unique replication protein having both plasmid- and virus-like domains:
Clue to viral ancestry or result of virus/plasmid recombination? Virology 285:270-277.

29. Padovan, A. C., Firrao, G., Schneider, B., and Gibb, K. S. 2000. Chromsome mapping of the sweet potato little leaf phytoplasma reveals genome heterogeneity within the phytopolasmas. Microbiology 146:893-902.

30. Ploaie, P. G. 1981. Mycoplasma-like organisms and plant diseases in Europe. Pages 61-104 in: Plant Diseases and Vectors: Ecology and Epidemiology. K. Maramorosch and K. F. Harris, eds. Academic Press, New York.

31. Rasa, E. A., and Esau, K. 1961. Anatomic effects of curly top and aster yellows viruses on tomato. Hilgardia 30:469-515

32. Renaudin, J., and Bové, J. M. 1994. SpV1 and SpV4, spiroplasma viruses with circular, single stranded DNA genomes, and their contribution to the molecular biology of spiroplasmas. Adv. Virus Res. 44:429-463.

33. Sass, A. E. 1958. Botanical Microtechnique, 3rd ed. Iowa State University Press, Ames.

34. Sawayanagi, T., Horikoshi, N., Kanehira, T., Shinohara, M., Bertaccini, A., Cousin, M.-T., Hiruki, C., and Namba, S. 1999. 'Candidatus Phytoplasma japonicum', a new phytoplasma taxon associated with Japanese Hydrangea phyllody. Int. J. Syst. Bacteriol. 47:1275-1285.

35. Schneider, H. 1959. Anatomy of bud-union bark of pear trees affected by decline. Phytopathology 49:550.

36. Schneider, H. 1977. Indicator hosts for pear decline: Symptomatology, histopathology, and distribution of mycoplasmalike organisms in leaf veins. Phytopathology 67:592-601.

37. Shiomi, T., Tanaka, M., Sawayanagi, T., Yamamoto, S., Tsuchizaki, T., and Namba, S. 1998. A symptomatic mutant of onion yellows phytoplasma derived from a greenhouse-maintained isolate. Ann. Phytopathol. Soc. Jpn. 64:501-505.

38. Spaink, H. P. 1995. The molecular basis of infection and nodulation by rhizobia: The ins and outs of sympathogenesis. Annu. Rev. Phytopathol. 33:345-368.

39. Uehara, T., Tanaka, M., Shiomi, T., Namba, S., Tsuchizaki, T., and Matsuda, I. 1999. Histopathological studies on two symptom types of phytoplasma associated with lettuce yellows. Ann. Phytopathol. Soc. Jpn. 65:465-469.

40. Wayadande, A. C., and Fletcher, J. 1995. Transmission of Spiroplasma citri lines and their ability to cross gut and salivary gland barriers within the leafhopper vector Circulifer tenellus. Phytopathology 85: 1256-1259.

41. Wayadande, A. C., Shaw, M. E., and Fletcher, J. 1993. Tests of differential transmission of three Spiroplasma citri lines by the leafhopper, Circulifer tenellus. (Abstr.) Phytopathology 83:468.

42. Ye, F., Laigret, F., Whiteley, J., Citti, C., Finch, L., Carle, P., Renaudin, J., and Bové, J. M. 1992. A physical and genetic map of the Spiroplasma citri genome. Nucleic Acids Res. 20:1559-1565.

43. Ye, F., Melcher, U., and Fletcher, J. 1997. Molecular characterization of a gene encoding a membrane protein of Spiroplasma citri. Gene 189:95100.

44. Ye, F., Melcher, U., Rascoe, J. E., and Fletcher, J. 1996. Extensive chromosome aberrations in Spiroplasma citri strain BR3. Biochem. Genet. 34:269-286.

45. Xuejun, S., Gumulak, J., Yu, H., French, C. T., Zou, N., and Dybvig, K. 2000. Gene rearrangements in the vsa locus of Mycoplasma pulmonis. J. Bacteriol. 182:2900-2908.

46. Zambryski, P., Tempe, J., and Schell, J. 1989. Transfer and function of TDNA genes from Agrobacterium $\mathrm{Ti}$ and $\mathrm{Ri}$ plasmids in plants. Cell 56:193-201. 